\title{
REPRODUCTIVE CHARACTER DISPLACEMENT AND SPECIATION IN PERIODICAL CICADAS, WITH DESCRIPTION OF A NEW SPECIES, 13-YEAR MAGICICADA NEOTREDECIM
}

\author{
David C. Marshall ${ }^{1,2}$ And John R. CoOley ${ }^{2,3}$ \\ Department of Biology and Museum of Zoology, University of Michigan, 1109 Geddes Avenue, Ann Arbor, Michigan $48109-1079$ \\ ${ }^{1}$ Email: dmarshal@umich.edu
}

\begin{abstract}
Acoustic mate-attracting signals of related sympatric, synchronic species are always distinguishable, but those of related allopatric species sometimes are not, thus suggesting that such signals may evolve to "reinforce" premating species isolation when similar species become sympatric. This hypothesis predicts divergences restricted to regions of sympatry in partially overlapping species, but such "reproductive character displacement" has rarely been confirmed. We report such a case in the acoustic signals of a previously unrecognized 13-year periodical cicada species, Magicicada neotredecim, described here as a new species (see Appendix). Where M. neotredecim overlaps M. tredecim in the central United States, the dominant male call pitch (frequency) of M. neotredecim increases from approximately $1.4 \mathrm{kHz}$ to $1.7 \mathrm{kHz}$, whereas that of $M$. tredecim remains comparatively stable. The average preferences of female $M$. neotredecim for call pitch show a similar geographic pattern, changing with the call pitch of conspecific males. Magicicada neotredecim differs from 13-year M. tredecim in abdomen coloration, mitochondrial DNA, and call pitch, but is not consistently distinguishable from 17-year M. septendecim; thus, like other Magicicada species, M. neotredecim appears most closely related to a geographically adjacent counterpart with the alternative life cycle. Speciation in Magicicada may be facilitated by life-cycle changes that create temporal isolation, and reinforcement could play a role by fostering divergence in premating signals prior to speciation. We present two theories of Magicicada speciation by life-cycle evolution: "nurse-brood facilitation", and "life-cycle canalization."
\end{abstract}

Key words._-Allochronic isolation, life-cycle evolution, Magicicada, reinforcement, reproductive character displacement, reproductive isolation, speciation.

\section{Received March 23, 1999. Accepted January 11, 2000.}

Periodical cicadas (Magicicada spp.) live underground as juveniles for either 13 or 17 years, after which they emerge for a brief adult life of approximately three weeks (Williams and Simon 1995). In northern and plains states, three morphologically and behaviorally distinct species coexist and emerge together once every 17 years (Fig. 1). These species are reproductively isolated in part by distinctive male acoustic signals and female responses (Alexander and Moore 1958, 1962). In the Midwest and South, three similar 13-year species have been described. Each species appears most closely related to another with the alternative life cycle; some of these species pairs can be distinguished only by life-cycle length (Table 1). This pattern suggests that speciation in Magicicada may involve a combination of geographic isolation and life-cycle changes that create temporal isolation (Alexander and Moore 1962; Lloyd and Dybas 1966; Lloyd and White 1976). Speciation involving allochronic isolation has been proposed for other organisms (e.g., field crickets: Alexander and Bigelow 1960; Alexander 1968; green lacewings: Tauber and Tauber 1977a,b), but remains controversial (e.g., Harrison 1979; Harrison and Bogdanowicz 1995).

The male sexual advertisement songs (or "calls") of sympatric Magicicada species are readily distinguishable, whereas those of the parapatric life-cycle siblings (e.g., 17-year $M$. cassini and 13-year M. tredecassini) are similar or indistinguishable (Alexander and Moore 1962). This relationship between sympatry and song distinctiveness is common in groups with long-range sexual signals, and it suggests a pro-

\footnotetext{
${ }^{2}$ Present address: Department of Ecology and Evolutionary Biology, University of Connecticut, Storrs, Connecticut 06269.

3 E-mail: jcooley@aya.yale.edu.
}

cess in which costly heterospecific sexual interactions lead to selection reinforcing differences that promote premating isolation (Dobzhansky 1940; Blair 1955). Selection of this form, long discussed as a potentially significant factor in speciation (Butlin 1989; Rice and Hostert 1993), also predicts greater reproductive trait divergence in sympatry, a pattern termed "reproductive character displacement" (Brown and Wilson 1956; sensu Loftus-Hills and Littlejohn 1992) when species' ranges only partly overlap. Waage (1979) argued that four criteria must be demonstrated to make a convincing case for reproductive character displacement: (1) the character(s) involved must play a significant role in aspects of premating isolation and they must be perceptible to the species across the range of phenotypic displacement observed in sympatry; (2) the allopatric character states must represent the precontact condition; (3) the apparent displacement in sympatry must not be explainable as part of a trend established for one or both species in allopatry; and (4) the displacement must have occurred as a result of the interaction of the species in sympatry, and not as a result of interactions with other features of the environment in sympatry.

Few cases of reproductive character displacement have been demonstrated (Alexander 1967; Walker 1974; Howard 1993); for example, just one set of related examples (Otte 1989 ) is known from the singing Orthoptera (grasshoppers, crickets, and katydids), a large, well-studied group with prominent acoustic signals. The small number of examples is surprising given other evidence of reinforcing selection (Coyne and Orr 1989, 1997). Some authors point to a lack of adequately studied cases (e.g., Walker 1974; Howard 1993; Gerhardt 1994), whereas others suggest that sexual signal evolution may be driven mainly by within-species processes (e.g., West-Eberhard 1983; Paterson 1993). 


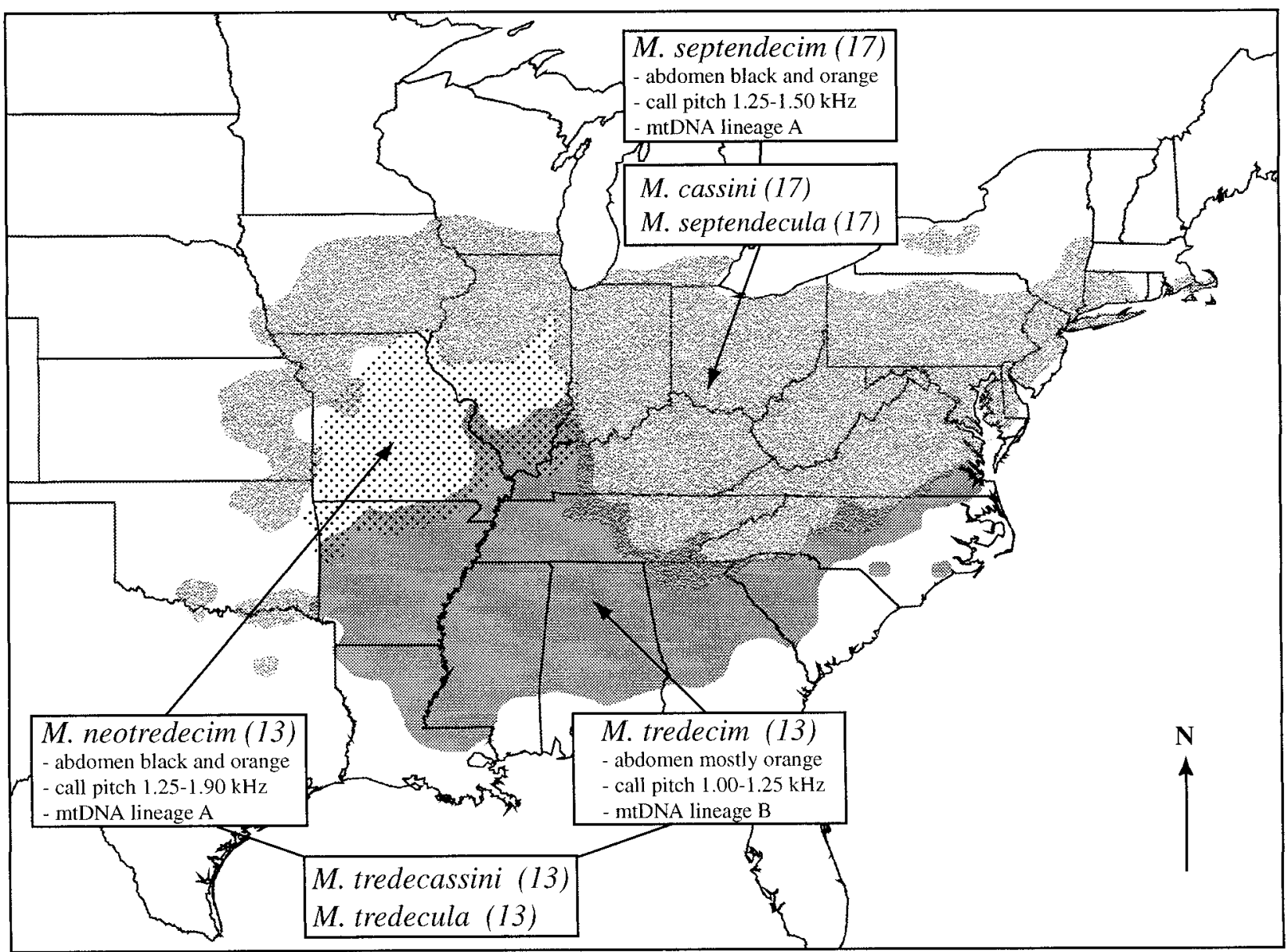

FIG. 1. Distribution of the seven periodical cicada (Magicicada) species (including one new species described here), summarized from county-level maps in Simon (1988) and from 1993-1998 field surveys in Illinois. The 17-year species are sympatric except in peripheral populations: M. cassini alone inhabits Oklahoma and Texas, whereas only M. septendecim is found in some northern populations (Dybas and Lloyd 1974). Two 13-year species (M. tredecassini and M. tredecula) are sympatric across the entire 13-year range, whereas the remaining 13-year species, $M$. tredecim and the new species $M$. neotredecim, overlap only in the central United States. County-level maps overestimate distribution limits, thus the overlap between the 13- and 17-year populations is probably exaggerated. The overlap of $M$. tredecim and $M$. neotredecim is plotted from recent field surveys (this study; Simon et al. 2000). Characters distinguishing M.decim species (see text) are noted; the M.-cassini and M.-decula siblings are distinguishable only by life cycle. Call pitch, dominant pitch of male call phrase; mtDNA lineage, types described in Martin and Simon (1990).

Here we report a new 13-year periodical cicada species, Magicicada neotredecim, that shows reproductive character displacement in male call pitch and female call pitch preferences in the central United States, where it overlaps its closest 13-year relative, M. tredecim (Fig. 1). Magicicada neotredecim appears most closely related to a 17 -year counterpart, M. septendecim, from which it may have originated by a life-cycle change (see also Martin and Simon 1988, 1990; Simon et al. 2000). These findings allow further refinement of hypotheses of life-cycle evolution and allochronic isolation in Magicicada and suggest a way in which reinforcement of signal differences in sympatry may facilitate speciation in Magicicada.

\section{Materials And Methods \\ Documenting Sympatric 13-Year Magicicada Species with Calls and Morphology}

Periodical cicada populations are extremely large; estimates of population density range from 8355 (Maier 1982) to 3,700,000 per hectare (Dybas and Davis 1962). Most populations contain three species, a M.-decim species that produces a narrow band of sound frequencies with a single dominant pitch between $1 \mathrm{kHz}$ and $2 \mathrm{kHz}$, and M.-cassini and M.-decula species that each produce broad-spectrum sounds above $3 \mathrm{kHz}$. (For convenience we refer to Magicicada sibling species groups using the following shorthand: M-decim: $M$. septendecim [17], M. tredecim [13], and M. neotredecim [13]; M-cassini: M. cassini [17] and M. tredecassini [13]; M.-decula: M. septendecula [17] and M. tredecula [13].)

While observing 13-year Magicicada in northern Arkansas in 1998, we found choruses (aggregations of singing males) with two peak frequencies in the M.-decim range (ca. 1.1 and $1.7 \mathrm{kHz}$ ), suggesting the presence of two M.-decim species, one previously undescribed (Fig. 2, background of Fig. 3). The location of this discovery suggested that the sympatric M.-decim would correspond to two forms of M. tredecim previously described using mitochondrial DNA (mtDNA) and abdomen coloration (amount of orange on the sternites) and 
TABLE 1. Traits distinguishing Magicicada neotredecim and other Magicicada species. Pronotal extension, the lateral extension of the pronotum behind the eye. For additional description and color photographs, see Alexander and Moore (1962).

\begin{tabular}{|c|c|c|c|c|c|}
\hline Species & $\begin{array}{c}\text { Life } \\
\text { cycle } \\
\text { (years) }\end{array}$ & $\begin{array}{l}\text { Abdominal sternite } \\
\text { color (each) }\end{array}$ & $\begin{array}{l}\text { Dominant } \\
\text { call pitch } \\
(\mathrm{kHz})\end{array}$ & $\begin{array}{l}\text { Pronotal } \\
\text { extension } \\
\text { color }\end{array}$ & $\begin{array}{l}\text { Length of } \\
\text { call (sec) }\end{array}$ \\
\hline $\begin{array}{l}\text { M. neotredecim Marshall and Cooley (new } \\
\text { species) }\end{array}$ & 13 & $\begin{array}{l}\text { orange with black lateral } \\
\text { band or center }\end{array}$ & $1.25-1.90$ & orange & $1.5-4^{1}$ \\
\hline M. tredecim (Walsh and Riley) & 13 & mostly orange & $1.00-1.25$ & orange & $1.5-4^{1}$ \\
\hline M. septendecim $(\mathrm{L})$. & 17 & $\begin{array}{l}\text { orange with black lateral } \\
\text { band or center }\end{array}$ & $1.25-1.50$ & orange & $1.5-4^{1}$ \\
\hline M. cassini (Fisher) & 17 & $\begin{array}{l}\text { black, rarely with weak }{ }^{2} \\
\text { orange lateral band }\end{array}$ & $>3.00$ & black & $2-4^{3}$ \\
\hline M. septendecula Alexander and Moore & 17 & $\begin{array}{l}\text { black with orange lateral } \\
\text { band }\end{array}$ & $>3.00$ & black & $7-14^{4}$ \\
\hline M. tredecula Alexander and Moore & 13 & $\begin{array}{l}\text { black and orange lateral } \\
\text { band }\end{array}$ & $>3.00$ & black & $7-14^{4}$ \\
\hline
\end{tabular}

${ }^{1}$ Roughly pure-tone, musical buzz terminating in a noticeable drop in pitch; no ticks. Usually two or three calls between flights.

${ }^{2}$ Orange band, if present, often interrupted medially.

${ }^{3}$ Rapid series of ticks followed by high-pitched, broad-spectrum buzz that rises and then falls in intensity and pitch. Usually one or two calls between flights.

${ }^{4}$ Repeated, rhythmic, high-pitched, broad-spectrum tick-buzz phrases, followed by repeated phrases containing only ticks. Usually one call between flights.

found to meet along a zone reaching from Arkansas to Indiana (Martin and Simon 1988).

To determine if the sympatric M.-decim call types correspond to these morphs, we recorded the calls of 150 males collected from a mixed chorus and tested for association of call pitch and abdomen color. We collected the males from privately owned woods 0.25 miles south of County Road 62 on County Road 51, at a powerline right-of-way, just outside the northwest boundary of the Harold E. Alexander Wildlife Management Area, Sharp County, Arkansas; we will refer to this location as the "powerline"' site.

All recordings were made using a Sony Professional Walkman cassette recorder with a Sony microphone and parabola, or a Sony $8-\mathrm{mm}$ videocassette recorder with built-in microphone. Because an individual male's calls do not vary significantly in dominant pitch, we isolated one call of each individual for spectral analysis. For each recording, we generated a power spectrum (plot of sound intensity vs. frequency) using Canary 1.1.1 (Cornell Bioacoustics Laboratory, Cornell University, Ithaca, NY) on a Macintosh com-

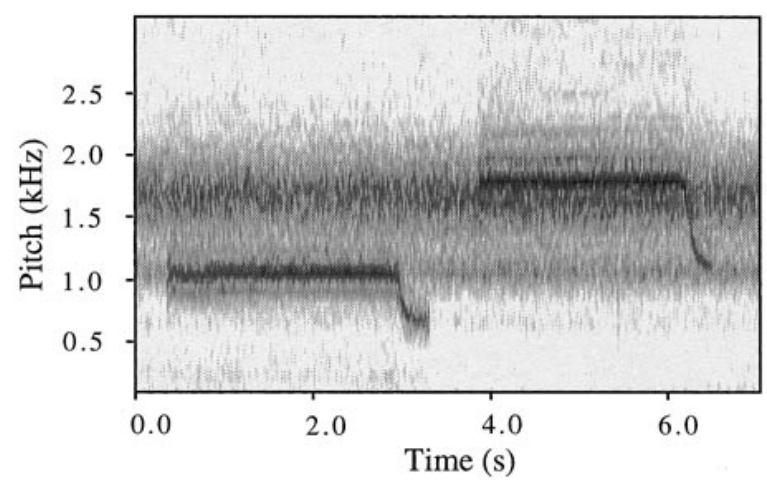

FIG. 2. Spectrogram (power spectrum vs. time) showing a twobanded, mixed-species chorus of male calls with one call of each M.-decim species (see text) standing out against the background chorus. Individual calls end with a downslur. Comparatively faint downslurs of background chorus males overlap and are not visible. puter and obtained the dominant pitch. Individual M.-decim calls consist of a 1-3-sec steady-pitch and nearly pure-tone " "main element" followed by a quieter 0.5 -sec frequency 'downslur' ending about $500 \mathrm{~Hz}$ lower than the main element pitch (Fig. 2) (Alexander and Moore 1958; Weber et al. 1988). The main element contains most of the sound energy; therefore, chorus recordings are dominated by the main element pitch. We scored the abdomen color of each individually recorded male using the method of Martin and Simon (1988), assigning each male a value from 1 (ca. 50\% black) to 4 (all orange).

We tested for an overall relationship between call pitch and abdomen color class using a Kruskal-Wallis test. Because the preliminary chorus recordings suggested two call types

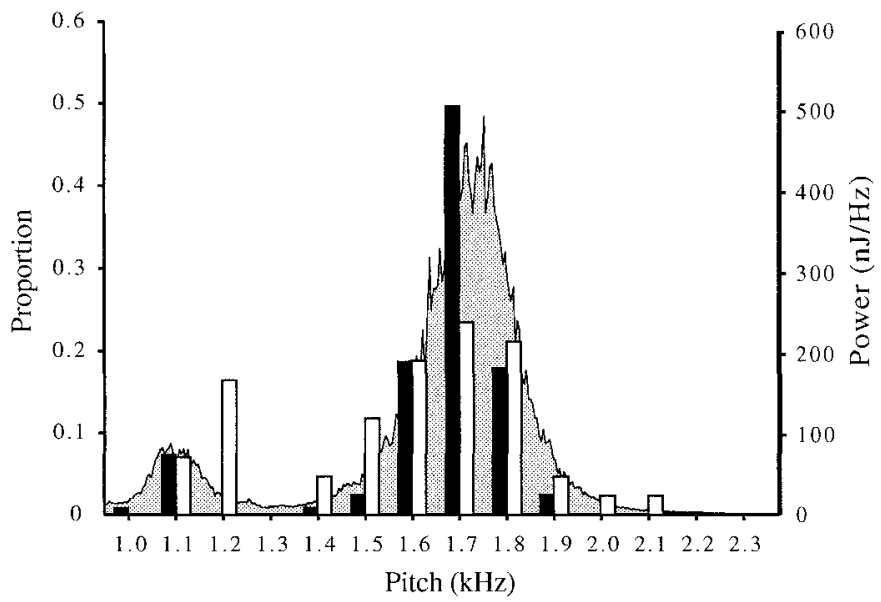

FIG. 3. Power spectrum (shaded area) of mixed Magicicada neotredecim and $M$. tredecim chorus at powerline study site, Sharp County, Arkansas, showing bimodal sound energy distribution with peaks at approximately $1.1 \mathrm{kHz}$ and $1.7 \mathrm{kHz}$. Accompanying frequency histograms are for male call pitches (black bars) and female average pitch preferences (white bars) of individuals collected at the site. Males were selected at random; females were selected for the playback experiment separately and with some bias toward the rarer species, which constitutes approximately $8 \%$ of the population. 
with few intermediates (a bimodal distribution of chorus sound energy), we also divided our male sample by an intermediate pitch of $1.4 \mathrm{kHz}$ and tested for a difference in abdomen coloration using a Mann-Whitney test. All statistical analyses were conducted using Systat (vers. 5.2.1, Macintosh version, Systat, Inc., San Francisco, CA).

\section{Measuring Female Call Pitch Preferences in Sympatry}

Sexually receptive female Magicicada produce timed "wing flick" signals in response to conspecific male calls; conspecific males respond to this signal by dropping out of the chorus, approaching the responding female, and beginning late-stage courtship behavior (Cooley 1999). Most such courtships lead to mating in studies using captive cicadas ( $\mathrm{J}$. R. Cooley and D. C. Marshall, unpubl. data). We used this signal as an assay of female mating receptivity to determine whether female preference for call pitch was correlated with abdomen color, using 74 M.-decim females collected from the Sharp County, Arkansas, powerline site. Using Sound Edit Pro (MacroMedia, San Francisco, CA), we produced 14 pure-tone model calling phrases differing only in dominant pitch $(1.0-2.3 \mathrm{kHz}$ main element pitch, in $0.1-\mathrm{kHz}$ increments); models were designed to mimic the form of normal calls (described above), but contained no pulse structure. In previous experiments, we have found that females respond similarly to playbacks of recorded and artificial calls (Cooley 1999). We played the models to individually marked, caged females in both haphazard and ordered sequences using a Macintosh Powerbook computer connected to an amplified portable speaker positioned $25 \mathrm{~cm}$ away from the cage (68$75 \mathrm{~dB}$, as determined by a Radio Shack sound level meter with A weighting). The playback experiments were carried out between $1100 \mathrm{~h}$ and $1600 \mathrm{~h}$ in bright overcast or sunny conditions against an acoustic background of a Magicicada chorus located in woods approximately $8 \mathrm{~m}$ away and containing all four 13-year species. Females were tested in groups of four, in random order with respect to abdomen coloration; each was exposed to the entire model set from two-to-10 times as time and mortality allowed. About a third (26/74) of the females did not respond to any call; these were dropped from the analysis. This response rate is similar to that observed in studies of 17-year M. septendecim females in Virginia and Illinois (Cooley 1999), where only one M.decim species is known. For each female, we averaged all model call pitches that elicited one or more wing-flick responses to determine the average pitch preference.

We scored female abdomen color using the method described above for males and tested for association between average pitch preference and abdomen color class by a Kruskal-Wallis test. In addition, using the intermediate pitch value $(1.4 \mathrm{kHz})$ observed in the male sample, we divided the female sample in two by average pitch preference and tested for a difference in abdomen coloration using a Mann-Whitney $U$ test.

\section{Estimating Species Distributions and Geographic Variation in Calls}

Once we had demonstrated the existence of two sympatric 13-year M.-decim species differing in call pitch, we estimated
TABLE 2. Dates of 1998 chorus recordings by region.

\begin{tabular}{ll}
\hline \hline \multicolumn{1}{c}{ Locations } & \multicolumn{1}{c}{ Dates } \\
\hline Alabama, Kentucky, Mississippi, North & \\
$\quad$ Carolina, Tennessee: & 31 May-3 June \\
All sites & \\
Arkansas: & 31 May \\
$\quad$ Clark and Pike Counties & $12-25$ May \\
Sharp, Fulton, and Lawrence Counties & 28 May \\
Other sites & \\
Illinois: & $29-30$ May \\
$\quad$ Randolph, Monroe, Jersey, Sangamon, \\
$\quad$ and Piatt Counties \\
$\quad$ Other sites \\
Maryland: \\
$\quad$ All sites & \\
Missouri: & 29 May-1 June \\
All sites & 1-7 June \\
\hline
\end{tabular}

the species' distributions and measured geographic variation in dominant chorus pitch using recordings (15-30 sec in duration) taken from 80 locations distributed throughout the 1998 Magicicada emergence. The 17- and 13-year life cycle groups each have formed several largely allopatric broods that emerge in different years; the broods are numbered according to year-class, from I to XVII for 17-year cicadas and from XVIII to XXX for 13-year cicadas. There are 12 extant 17 -year broods and just three 13-year broods, so many yearclasses are empty (see individual brood maps in Simon 1988). The 1998 13-year emergence involved the large brood XIX, which reaches from Maryland to Oklahoma. Recording dates are given in Table 2 .

For mixed choruses, we used the relative intensities of the two species-specific M.-decim dominant chorus pitches to estimate relative proportions of the species; these intensities were measured from the power spectrum of each chorus recording. This approach assumes that both species show the same relationship between male abundance and chorus intensity. Because field conditions did not allow direct comparisons of male sound output of the two M.-decim species, we tested the assumption indirectly: In the mixed-species powerline chorus from Sharp County, Arkansas, we compared the distribution of individual call pitches of a random collection of 123 males to the distribution of acoustical energy in the chorus power spectrum, using a KolmogorovSmirnov test. The effectiveness of using chorus recordings to estimate M.-decim chorus composition is further improved if the two species do not form mutually exclusive spatial aggregations. To test this assumption, we recorded a continuous chorus sample along a $200 \mathrm{~m}$ woodside trail in the Harold E. Alexander Wildlife Management Area, Sharp County, Arkansas, while pointing the parabola/microphone assembly into the treetops at a $45^{\circ}$ angle. We recorded one side while walking in one direction and then recorded the other side while returning. From samples of this recording taken at $7 \mathrm{~m}$ intervals, we measured the intensities of the $M$. neotredecim and $M$. tredecim frequency bands from power spectra; this yielded 47 samples because of gaps in the forest on one side $(350 \mathrm{~m}$ total). If the $M$. neotredecim and $M$. 
tredecim at the site were not uniformly distributed with respect to one another on a local scale, we would expect to observe significant variation among locations in the relative intensities of the two species' chorus bands.

\section{Additional Tests for Demonstrating Reproductive Character Displacement}

As described below in Results, geographic sampling of choruses revealed an apparent pattern of reproductive character displacement in M. neotredecim call pitch, with more southern populations (those overlapping M. tredecim) exhibiting higher call pitch. Further confirmation of the pattern necessitated additional tests deriving from Waage's (1979) criteria 1 and 3 (see Introduction).

To determine if female call pitch preferences change geographically with male call pitch in $M$. neotredecim, a predicted pattern if male call pitch functions in mate recognition, we measured average pitch preferences of $33 \mathrm{M}$. neotredecim females collected from a woodlot 0.8 miles south of White Heath, Illinois, on Route 1300E (Piatt Co.), beyond the range of $M$. tredecim. Twelve of these females were responsive during the test; the remainder were discarded. We completed the playback experiments at nearby Lodge Park County Forest Preserve against a background chorus containing $M$. neotredecim, M. tredecassini, and M. tredecula. We used a MannWhitney $U$-test to determine if the average pitch preference of the Piatt County females differed from that of the Sharp County, Arkansas, powerline site females. Because of time constraints, we were unable to study allopatric $M$. tredecim females.

To test the alternative possibility that call pitch variations could be explained as a secondary effect of a north-south cline in male size, we compared the call pitches and body sizes of $61 \mathrm{M}$. neotredecim and $26 \mathrm{M}$. tredecim males from sympatry at the Sharp County, Arkansas, powerline site with those of 17 M. neotredecim males collected in Allerton Park, Piatt County, Illinois, where no M. tredecim are present. We used three characters to estimate size: right wing length, thorax width between the wing articulations, and first abdominal sternite width between the sutures that join the sternite to the terga. We conducted pairwise comparisons among populations using Mann-Whitney $U$-tests. For each population, we tested for associations between size-related traits and call pitch using linear regressions.

\section{RESUlts}

\section{Behavioral and Morphological Evidence for Sympatric Magicicada-decim Species}

The Kruskal-Wallis test indicated a strong relationship between male call pitch and abdomen color class at the Sharp County, Arkansas, powerline site (Table 3). Furthermore, the 150 individual male call pitches fell into two distinct groups with no intermediate pitch values from $1.20 \mathrm{kHz}$ to $1.42 \mathrm{kHz}$ (Fig. 3), confirming the bimodal chorus energy distribution observed in chorus recordings. A Mann-Whitney comparison showed that these two groups differed significantly in abdomen coloration (Table 3): Males producing calls with low dominant pitch had the orange abdomen color characteristic
TABLE 3. Thirteen-year male M.-decim (see text for species) call types are species corresponding to abdomen color morphs identified by Martin and Simon (1988). (A) Kruskal-Wallis test, with call pitch as dependent variable, indicates overall relationship between pitch and abdomen coloration (test statistic $=45.969, P<0.001$ ); the break between the two species occurs in abdomen color class 3. (B) Dividing the bimodal male M.-decim pitch sample by an intermediate pitch (1.4 $\mathrm{kHz}$ ) yields two groups differing significantly in abdomen color (Mann-Whitney $U=3104.0, P<0.001$ ).

\begin{tabular}{|c|c|c|c|}
\hline $\begin{array}{l}\text { (A) } \\
\text { Abdomen } \\
\text { color } \\
\text { class }\end{array}$ & Count & $\begin{array}{c}\text { Call } \\
\text { pitch } \\
(\text { mean } \pm \mathrm{SD})\end{array}$ & $\begin{array}{l}\text { Rank- } \\
\text { sum }\end{array}$ \\
\hline $\begin{array}{l}1 \\
2 \\
3 \\
4\end{array}$ & $\begin{array}{r}11 \\
103 \\
15 \\
21\end{array}$ & $\begin{array}{l}1.73 \pm 0.09 \\
1.70 \pm 0.08 \\
1.46 \pm 0.33 \\
1.16 \pm 0.20\end{array}$ & $\begin{array}{c}1138.5 \\
8863.5 \\
880 \\
443\end{array}$ \\
\hline $\begin{array}{l}\text { (B) } \\
\text { Dominant call } \\
\text { pitch in kHz } \\
\text { (mean } \pm \mathrm{SD})\end{array}$ & $\begin{array}{l}\text { Abdomen } \\
\text { color }\end{array}$ & $\begin{array}{c}\text { Species } \\
\text { designation }\end{array}$ & $n$ \\
\hline $\begin{array}{l}1.10( \pm 0.04) \\
1.70( \pm 0.07)\end{array}$ & $\begin{array}{l}3.69( \pm 0.55) \\
2.02( \pm 0.48)\end{array}$ & $\begin{array}{l}\text { M. tredecim } \\
\text { M. neotredecim }\end{array}$ & $\begin{array}{r}26 \\
124\end{array}$ \\
\hline
\end{tabular}

of Martin and Simon's (1988) mtDNA lineage B, now recognized to be the previously described M. tredecim (Alexander and Moore 1962). M.-decim males producing higherpitch calls had the darker abdomen color of Martin and Simon's mtDNA lineage A, and constitute a new species here named M. neotredecim (description in Appendix). Among approximately 250 male cicadas observed during our study, we found just four putative intermediates: two high-pitch males with orange abdomens (category 4), one low-pitch male with a darker abdomen (category 2), and one male with an intermediate call $(1.43 \mathrm{kHz})$.

\section{Female Call Pitch Preferences and Morphology in Sympatry}

Most responding females wing-flicked (WF) to model calls of several different pitches (mean $=6.8$ different call pitches, $\mathrm{SD}=3.2$ ). The average range of response (highest pitch eliciting WF - lowest pitch eliciting WF) was similar (mean $=7.4, \mathrm{SD}=3.5$ ), because most females responded to a continuous rather than fragmented range of frequencies. There was a strong relationship between average pitch preference and abdomen color (Table 4). The bimodal phenotypic distribution apparent in male M.-decim call pitch appeared in the distribution of average female pitch preferences as well, indicating two classes of females (Fig. 3). When the female sample was divided at the intermediate pitch of $1.4 \mathrm{kHz}$, the resulting female groups differed in abdomen coloration just as in the male sample: Females responding on average to low-pitch calls $(M$. tredecim) were significantly more orange than females responding on average to high-pitch calls ( $M$. neotredecim; Table 4).

\section{Species Distributions and Geographic Variation in Male Calls}

Using chorus recordings to estimate species abundance.The random sample of individual male calls from the Sharp 
TABle 4. Thirteen-year female M.-decim (see text for species) call pitch preference types are species corresponding to abdomen color morphs identified by Martin and Simon (1988). (A) Kruskal-Wallis test, with pitch preference as dependent variable, indicates overall relationship between pitch preference and abdomen coloration (test statistic $=10.58, P \leq 0.014$ ). (B) Dividing the bimodal female M.decim pitch preference sample (Fig. 3) by an intermediate pitch preference $(1.4 \mathrm{kHz})$ yields two groups differing significantly in abdomen color (Mann-Whitney $U=317.000, P \leq 0.001$ ).

\begin{tabular}{|c|c|c|c|}
\hline \multicolumn{4}{|l|}{ (A) } \\
\hline $\begin{array}{l}\text { Abdomen } \\
\text { color } \\
\text { class }\end{array}$ & Count & $\begin{array}{c}\text { Average pitch } \\
\text { preference } \\
(\text { mean } \pm \text { SD) }\end{array}$ & $\begin{array}{c}\text { Rank- } \\
\text { sum }\end{array}$ \\
\hline 1 & 5 & $1.67 \pm 0.15$ & 136.5 \\
\hline 2 & 22 & $1.69 \pm 0.22$ & 633.5 \\
\hline 3 & 14 & $1.62 \pm 0.26$ & 341 \\
\hline 4 & 7 & $1.28 \pm 0.19$ & 65 \\
\hline \multicolumn{4}{|l|}{ (B) } \\
\hline $\begin{array}{c}\text { Call pitch } \\
\text { preference } \\
\text { in } \mathrm{kHz} \\
(\text { mean } \pm \mathrm{SD})\end{array}$ & $\begin{array}{l}\text { Abdomen } \\
\text { color }\end{array}$ & $\begin{array}{c}\text { Species } \\
\text { designation }\end{array}$ & $n$ \\
\hline $1.19( \pm 0.06)$ & $3.40( \pm 0.84)$ & M. tredecim & 10 \\
\hline $1.72( \pm 0.15)$ & $2.24( \pm 0.71)$ & M. neotredecim & 38 \\
\hline
\end{tabular}

County, Arkansas, powerline population indicated a strong relationship between relative abundance of the M.-decim species and the distribution of sound energy in the chorus: The standardized histogram of call pitches of individually recorded males was indistinguishable from the standardized quadratic chorus power spectrum (Kolmogorov-Smirnov test, $P>0.05$; Fig. 3).

Although the proportions of the two M.-decim species vary on a scale of miles (e.g., Fig. 4 insets), the 13-year M.-decim species do not appear to cluster significantly within a location. In the $350-\mathrm{m}$ continuous recording the proportion of M.-decim chorus sound produced by the rarer species $(M$. neotredecim) remained between $10 \%$ and $36 \%$ of the total chorus sound output $($ mean $=19.0 \%, \mathrm{SD}=6.0, n=47$ ), and the chorus intensities of the two species were not significantly negatively correlated (Pearson coefficient = $-0.229, P=0.121)$.

Geographic overlap and reproductive character displacement in male call pitch between $M$. neotredecim and $M$. tredecim. -We found M. neotredecim in Missouri, Illinois, western Kentucky, and northern Arkansas (Fig. 4; see also Simon et al. 2000). The southernmost $M$. neotredecim populations overlap $M$. tredecim in a zone $50-150 \mathrm{~km}$ wide reaching from northern Arkansas into southern Missouri, southern Illinois, and western Kentucky. The remainder of brood XIX contains $M$. tredecim and not $M$. neotredecim.

Geographic variation in dominant chorus pitch of $M$. neotredecim occurs in a pattern of reproductive character displacement (Fig. 5). Magicicada neotredecim choruses have the highest dominant pitch (ca. $1.7 \mathrm{kHz}$ ) in sympatry with $M$. tredecim; in this region individual $M$. neotredecim males have call pitches as high as $1.9 \mathrm{kHz}$. North of the overlap zone, $M$. neotredecim dominant chorus pitch decreases to

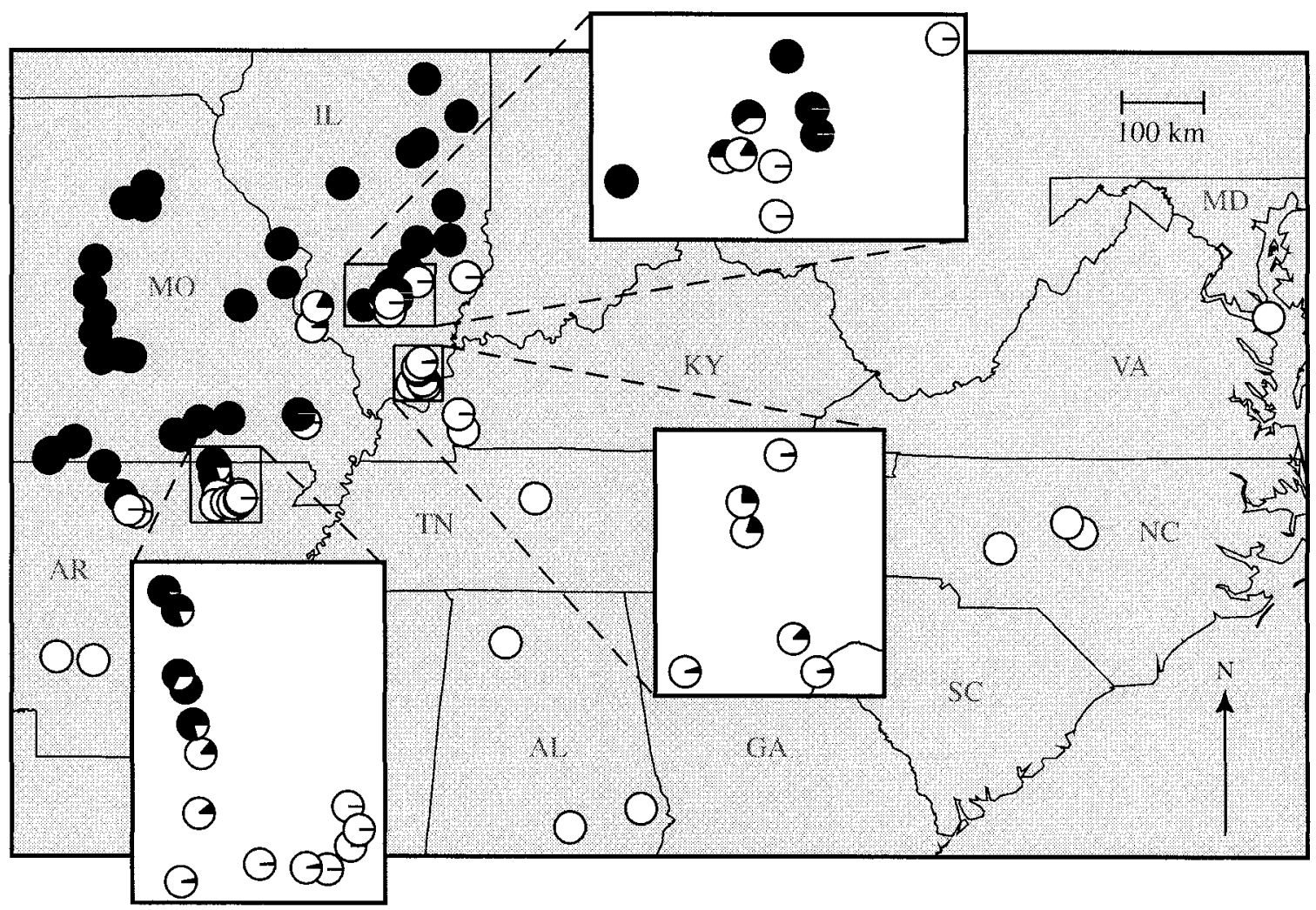

FIG. 4. Relative proportions of Magicicada neotredecim (black) and M. tredecim (white) estimated from chorus recordings of the 1998 emergence of Magicicada 13-year brood XIX. 


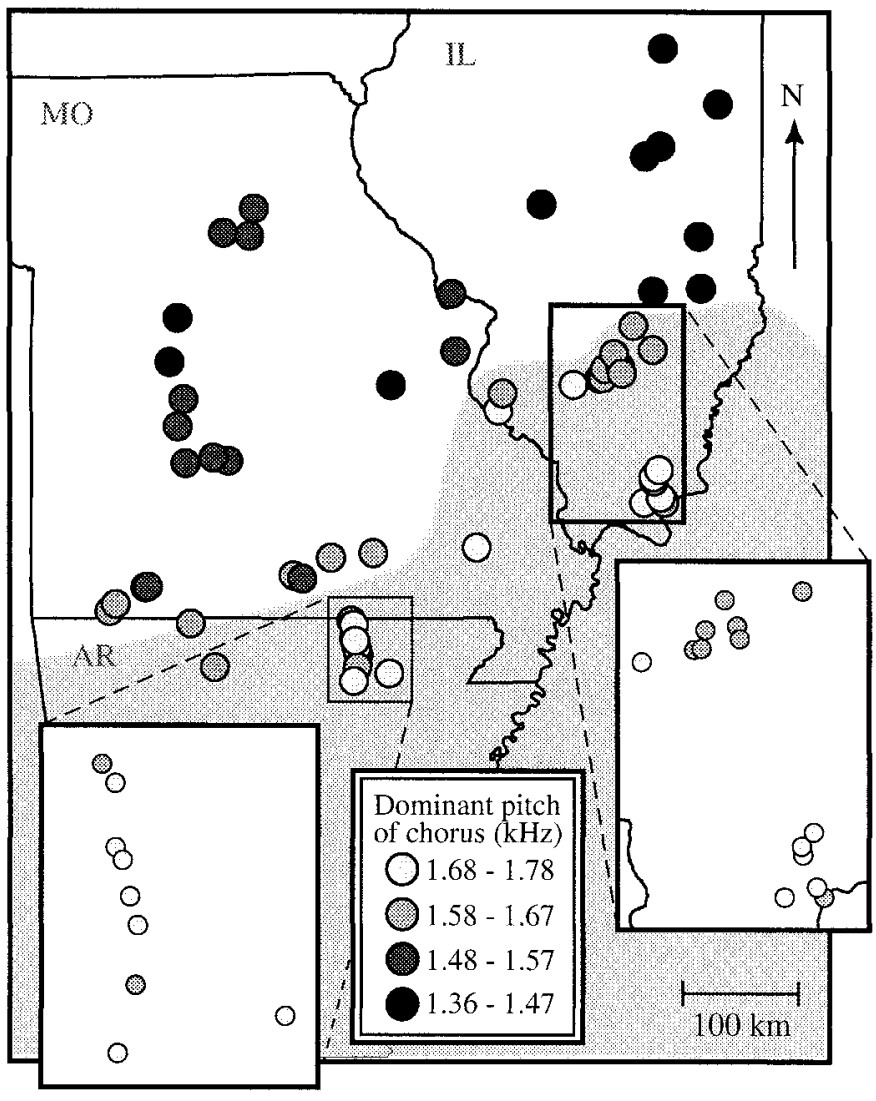

FIG. 5. Geographic variation in dominant chorus pitch of Magicicada neotredecim, showing higher-pitch calls in and near the region of overlap with $M$. tredecim. Lighter shaded circles indicate higher-pitch calls. Shaded region is approximate $M$. tredecim range. Weak choruses are not plotted.

approximately $1.4 \mathrm{kHz}$ in Illinois and $1.5 \mathrm{kHz}$ in Missouri, a statistically significant shift (Table 5). Most of the change occurs immediately north of the zone of $M$. tredecim $/ M$. neotredecim sympatry.

Call pitch variation in M. tredecim is more subtle (Fig. 6), less than $25 \%$ of that observed in M. neotredecim. Magicicada tredecim choruses in deep sympatry with $M$. neotredecim have a low dominant pitch, and $M$. tredecim dominant chorus pitch slightly increases south and east in the overlap zone in Missouri and Illinois. However, some allopatric M. tredecim choruses in the southeast also contain very low-pitch calls, and there is no overall difference between choruses in sympatry and allopatry with $M$. neotredecim (Table 5).

Most of the chorus samples likely included the calls of hundreds or thousands of males. However, many of the populations from Missouri and Alabama were recorded late in the emergence when comparatively few males remained (Table 2). For these locations, the chances of overlooking a rare species were greater.

\section{Additional Tests of Reproductive Character Displacement}

Female $M$. neotredecim call pitch preferences change geographically with male call pitch: In sympatry with $M$. tredecim, (powerline site, Sharp Co., AR) female M. neotredecim were most responsive to an average pitch of $1.72 \pm 0.15 \mathrm{kHz}$ $(n=38)$, while in allopatry (Piatt Co., IL) female preference averaged $1.31 \pm 0.10 \mathrm{kHz}(\mathrm{n}=12$; Mann-Whitney $U=451$, $P \leq 0.001)$. Allopatric $M$. neotredecim also differed significantly $(U=104, P \leq 0.003)$ in pitch preference from the Arkansas (powerline site) M. tredecim (mean $1.19 \pm 0.06$ $\mathrm{kHz}, n=10)$.

Magicicada tredecim and M. neotredecim in sympatry were significantly different in all size measurements, although the magnitudes of these differences were not as great as those observed in call pitch (Fig. 7). Magicicada neotredecim populations from Illinois and Arkansas differed in call pitch but not in size (Fig. 7). We found no significant relationship between call pitch and any measure of body size within species in any population using linear regressions.

\section{DISCUSSION}

\section{Call Pitch and 13-year Magicicada-decim Species}

The conclusion that $M$. tredecim and $M$. neotredecim are the 13-year M.-decim forms identified by Martin and Simon $(1988,1990)$ is supported by the correlation of call pitch differences with abdomen coloration differences and by the fact that the species' distributions within brood XIX as determined using call phenotypes closely match those estimated by Martin and Simon using morphology and mtDNA (Martin and Simon 1988, 1990). The scarcity of call and preference intermediates (Figs. 2, 3) suggests that viable adult hybrids are rare (see also Simon et al. 2000); this could be due to hybrid failure or lack of interbreeding.

Because females of the two 13-year M.-decim species were able to distinguish call models varying only in dominant

TABLE 5. Sympatric and allopatric Magicicada neotredecim populations differ significantly in dominant chorus pitch (Mann-Whitney $U=21$, $P \leq 0.001)$, whereas those of $M$. tredecim do not $(U=120.5, P \leq 0.824)$. The comparison is conservative because some apparently allopatric populations of $M$. neotredecim were recorded late in the emergence when cicadas were sparse and rare $M$. tredecim may have been missed.

\begin{tabular}{|c|c|c|c|c|}
\hline & \multicolumn{2}{|c|}{ M. neotredecim } & \multicolumn{2}{|c|}{ M. tredecim } \\
\hline & Sympatry & Allopatry & Sympatry & Allopatry \\
\hline $\begin{array}{l}\text { Dominant chorus } \\
\text { pitch in } \mathrm{kHz} \\
(\text { mean } \pm \mathrm{SD})\end{array}$ & $1.71 \pm 0.05$ & $1.52 \pm 0.09$ & $1.12 \pm 0.03$ & $1.12 \pm 0.04$ \\
\hline $\begin{array}{l}\text { Range }(\mathrm{kHz}) \\
n\end{array}$ & $\begin{array}{c}1.65-1.78 \\
23\end{array}$ & $\begin{array}{c}1.36-1.74^{1} \\
34\end{array}$ & $\begin{array}{c}1.06-1.17 \\
23\end{array}$ & $\begin{array}{c}1.06-1.16 \\
11\end{array}$ \\
\hline
\end{tabular}

${ }^{1}$ Only two of the 34 allopatric M. neotredecim populations have dominant pitch values higher than $1.62 \mathrm{kHz}$; both are from southern Missouri. 


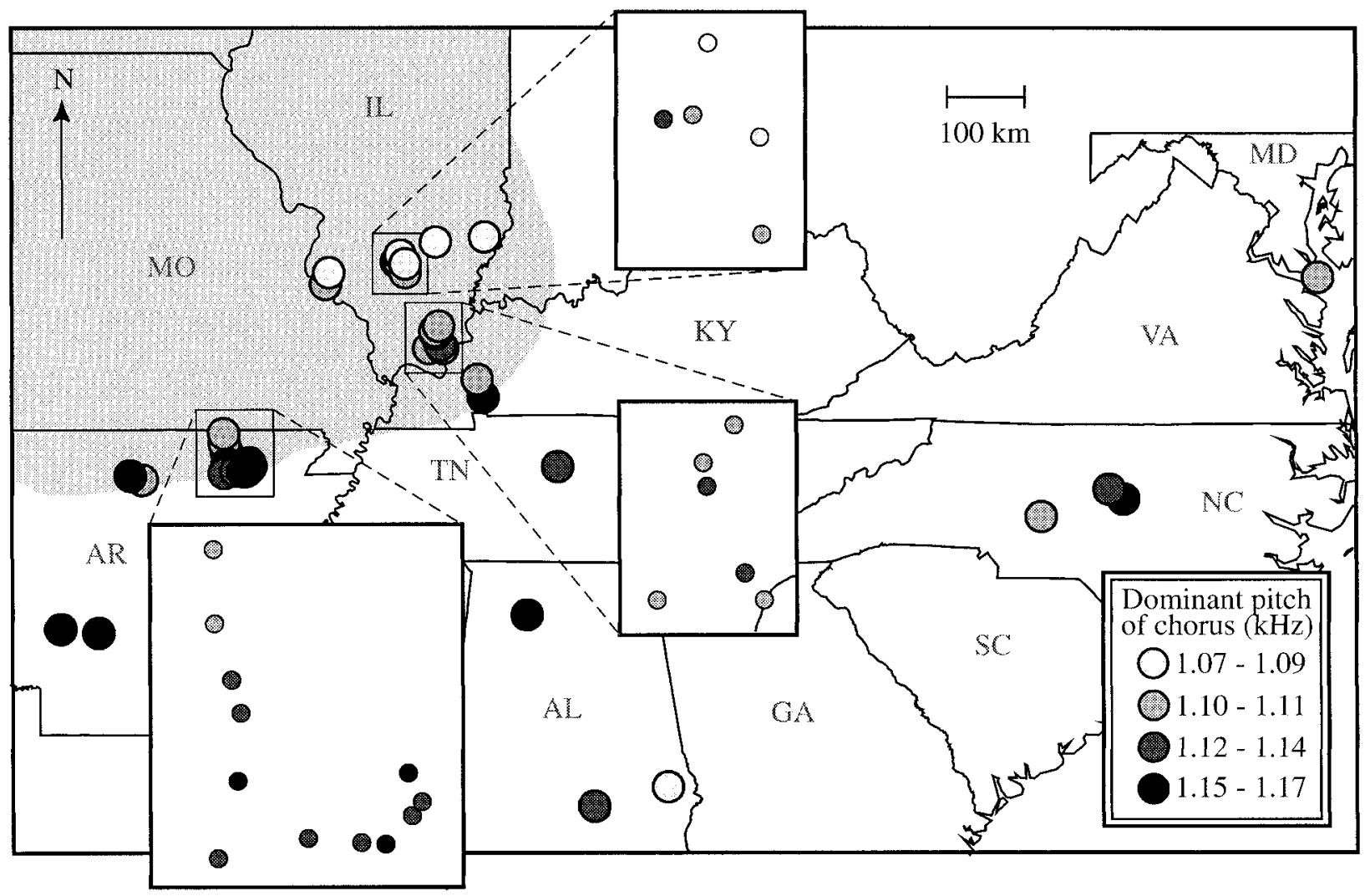

FIG. 6. Geographic variation in dominant chorus pitch of Magicicada tredecim, showing lower-pitch calls in sympatry with $M$. neotredecim. Lighter shaded circles indicate lower-pitch calls. Shaded area is approximate M. neotredecim range. Note that range of variation is only one-fourth of that shown in Figure 5. Weak choruses are not plotted.

pitch, and because female call pitch preferences correlate with abdomen coloration types, call pitch differences are likely an important cause of species specificity in M.-decim mate recognition. In addition to the dominant pitch, natural calls contain temporal patterns that result from individual tymbal contractions and the buckling of tymbal ribs (Young and Josephson 1983; Weber et al. 1988); our model calls did not contain such patterns. However, differential responses to our model calls demonstrate that such temporal characteristics are not required for mate recognition, and the call pitch differences are unlikely to be explained as secondary effects of differences in tymbal pulse rate. Variations in M. septendecim tymbal contraction rate do not alter dominant call pitch, which may be determined by physical properties of the resonating abdomen and its large air sac (Young and Josephson 1983). Furthermore, we found no relationship between air temperature (which affects tymbal contraction rate) and chorus pitch in 11 recordings taken from the same location at different times (Fig. 8). Little is known of the relative roles of temporal patterning and frequency content in cicada calls in general, although both function in Australian bladder cicadas (Cystosoma; Doolan and Young 1989), each in a different context.

\section{Reproductive Character Displacement in Magicicada neotredecim}

The increase of $M$. neotredecim call pitch in sympatry with M. tredecim (a change of nearly 25\%) meets the criteria es- tablished by Waage (1979) for reproductive character displacement (see Introduction). The model call playback experiments demonstrate that the difference in 13-year M.-decim call pitch in sympatry likely plays a role in mate recognition, and that the range of variation is perceptible to the species. The fact that allopatric populations of $M$. neotredecim in Illinois are indistinguishable in call pitch from 17-year $M$. septendecim (dominant chorus pitch 1.30-1.45 kHz; unpubl. data), the new species' closest relative (Martin and Simon 1988, 1990), supports the conclusion that the high call pitch of $M$. neotredecim in the overlap zone is derived. No trends exist in allopatry that can explain the pattern of displacement; rather, the displacement is associated with the zone of sympatry. In Illinois and eastern Missouri, nearly all of the geographic change in dominant chorus pitch occurs in an approximately $50-\mathrm{km}$ zone immediately north of the $M$. tredecim range limit, and variation among allopatric populations or among sympatric populations is comparatively minor (Fig. 5); the pattern in central Missouri is less striking, however (see below). In addition, the change in call pitch does not appear to be an incidental effect of a latitudinal cline in body size (Fig. 7). Finally, the requirement that the divergence be attributable to reproductive interactions of the species is indirectly supported by the fact that average $M$. neotredecim and $M$. tredecim calls in sympatry differ just enough to avoid frequency overlap, with $M$. neotredecim downslurs ending at approximately the dominant call pitch of M. tredecim (Fig. 2). 
A.

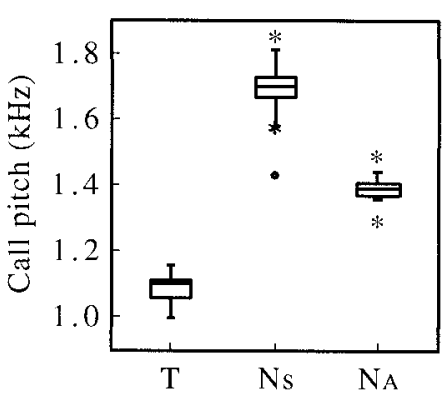

C.

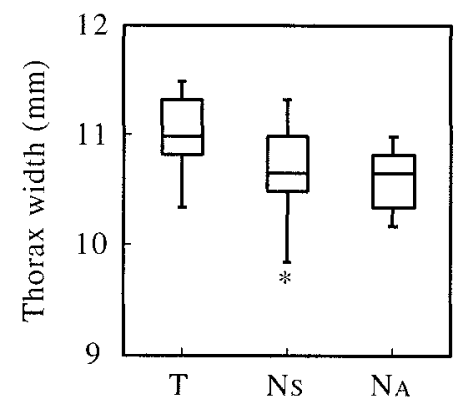

B.

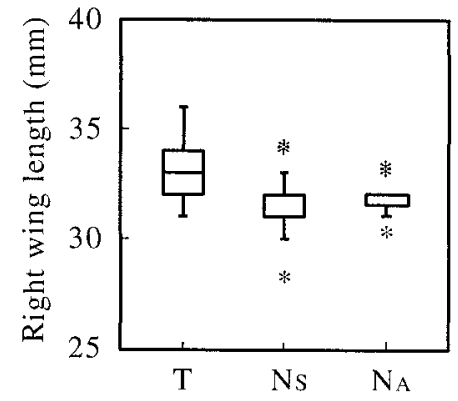

D.

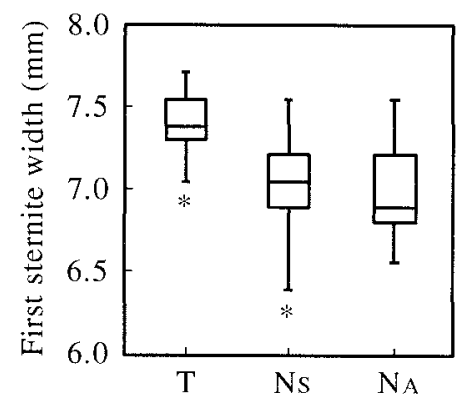

FIG. 7. Box plots of male call pitch (A), right wing length (B), thorax width (C), and first sternite width (D) of Magicicada tredecim ("T," Sharp County, AR; $n=26$ ), M. neotredecim in sympatry with M. tredecim ("Ns," Sharp County, AR; $n=61$ ), and M. neotredecim in allopatry ("NA,"' Piatt County, IL; $n=17$ ). Shown for each sample are the median, the lower and upper hinges (first and third quartiles), the inner fences $( \pm 1$ step from hinge, a "step" $=[1.5 \times$ difference between hinges $]$ ), and outliers within $(*)$ or beyond $(\circ)$ the outer fence $( \pm 2$ steps from hinge). Male call pitch samples are significantly different $(P<0.001$, Mann-Whitney) in all pairwise combinations, whereas size measurements show no significant differences within M. neotredecim. M. tredecim is significantly larger than M. neotredecim in all size traits (for each, $P<0.001$; Mann-Whitney).

A potential challenge to the conclusion of reproductive character displacement arises because some central Missouri populations apparently well outside the range of M. tredecim have a partially elevated $M$. neotredecim dominant chorus

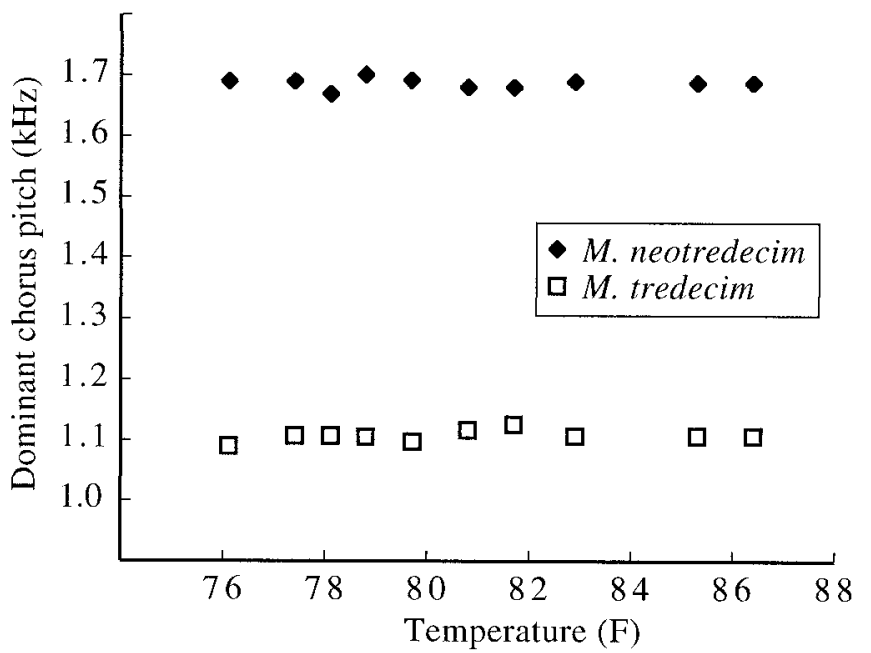

FIG. 8. Magicicada neotredecim and M. tredecim dominant chorus pitches plotted from ten recordings taken at different ambient temperatures in the same mixed-species chorus (Harold E/ Alexander, Wildlife Management Area, Sharp County, AR; May 1998). Linear regression indicates no significant relationship between temperature and chorus pitch within either species (M. neotredecim, $r^{2}=0.008$, $P \leq 0.804 ; M$. tredecim, $\left.r^{2}=0.15, P \leq 0.274\right)$ pitch (ca. $1.5 \mathrm{kHz}$ ). This pattern could be explained if $M$. neotredecim colonized Missouri from Illinois populations that were themselves adjacent to the range of $M$. tredecim or if undiscovered $M$. tredecim populations exist in Missouri near the locations we sampled. Future surveys should investigate the latter possibility. Because $M$. tredecim appears to reach its northern limits on Mississippi and Wabash lowlands, it may be found only in restricted locations near rivers elsewhere in the northern part of its range.

Also of interest is that the dominant chorus pitch of $M$. neotredecim does not correlate with the relative abundance of the two 13-year M.-decim species in mixed populations (linear regression, $r^{2}=0.053, P>0.3, n=21$ ). This appears to undermine the conclusion that the displacement is attributable to reproductive interactions of the two species (Waage 1979 , criterion 4), if the strength of reinforcing selection on one species is expected to depend on the abundance of the other (Howard 1993; Noor 1995). However, the prediction of frequency dependence is not appropriate under some circumstances. Average $M$. neotredecim calls in sympatry are displaced just enough to avoid frequency overlap with $M$. tredecim (Fig. 2), suggesting that reinforcing selection may cease at that point; if only small numbers of $M$. tredecim are necessary to drive this change in $M$. neotredecim, then a correlation between relative abundance and degree of displacement would be detectable only among populations with extremely rare $M$. tredecim. In addition, if conditions influencing the relationship between relative abundance and displace- 
ment vary across regions, then the correlation may have been obscured by our combined analysis of all mixed populations; a more local scale of analysis could reveal the expected relationship. The data from southern Illinois (Fig. 5 inset), for example, suggest greater displacement in southern populations where $M$. neotredecim is more rare; however, this possibility will not be resolved without additional data.

Magicicada neotredecim call pitch has changed much more than that of $M$. tredecim; such asymmetries are not unusual in cases of reproductive character displacement (e.g., Littlejohn 1965; Littlejohn and Loftus-Hills 1968; Fouquette 1975; Waage 1979; Noor 1995). In general, because the strength of selection on each species depends on factors that can differ between them, symmetrical displacement is probably unlikely (Grant 1972; Howard 1993). Possible explanations in the Magicicada case include the following: (1) greater numerical abundance of $M$. tredecim relative to $M$. neotredecim during critical stages of the interaction, perhaps because $M$. neotredecim originally invaded established $M$. tredecim populations and not vice versa; (2) greater $M$. tredecim female selectiveness upon initial contact; (3) greater constraints on the evolution of lower call pitch.

\section{Reinforcement and Speciation}

The criteria for reproductive character displacement (sensu Howard 1993) as established by Waage (1979) reflect an expected outcome of natural selection reducing inefficiencies arising from heterospecific sexual interactions; such selection is sometimes referred to generally by the terms "reinforcement', or "'reinforcing selection.' In general, the reproductive inefficiencies driving such selection could range from interbreeding with partial hybrid success and limited introgression to interbreeding with complete hybrid failure to simple reproductive interference (e.g., crossmating with morphological incompatibility or signal interference without crossmating). Because reinforcing selection can reduce gene flow between populations under certain conditions (Rice and Hostert 1993; Liou and Price 1994), such selection has been considered a process of speciation (Dobzhansky 1940; Blair 1955; Butlin 1995; Kelly and Noor 1996). In accordance with this view, Butlin $(1987,1989)$ argues for a redefinition of terms: 'Reinforcement' should apply only when premating isolation is enhanced despite interbreeding and gene flow, and the term "reproductive character displacement"' should refer to the divergence of mate recognition systems when hybrids are sterile. Under this terminology, only reinforcement is a candidate speciation mechanism because speciation is already completed if gene flow is not possible (Butlin 1989).

This approach has two weaknesses. First, reinforcement may be best viewed not as a mechanism of speciation, but instead as a process that only species undergo. Most species definitions reflect a general concept of species as "population-level evolutionary lineages", (de Queiroz 1998); the best evidence (when available) of the distinctiveness of such lineages is their ability to remain distinct and/or diverge even in sympatry. Reinforcement occurs only if, prior to contact, divergence in allopatry or allochrony has caused two populations to accumulate sufficient reproductive incompatibili- ties; thus, the occurrence of reinforcement is itself evidence that the populations were species (able to remain distinct in sympatry/synchrony) before contact. Therefore, reinforcement is more an effect of speciation than a cause, regardless of whether the populations exchange genes at any point. This view of reinforcement and speciation does not require distinctions based on degree of hybrid failure. Furthermore, this approach is compatible with evidence of widespread natural hybridization (e.g., Grant and Grant 1992; Arnold 1997), which suggests that species status should not be rejected simply on the basis of incomplete hybrid sterility or naturally occurring gene flow.

Second, the new definitions are impractical because neither term can be applied to a given case of reproductive character divergence if the extent of past gene flow between the species is unknown. We do not know if $M$. neotredecim and $M$. tredecim exchanged genes upon first contact. Evidence that hybridization is currently rare or absent does not prove that it did not occur in the past, so additional analysis will not necessarily resolve the question. Therefore, there may be value in retaining a general concept of reinforcement as a process of reproductive character divergence driven by selection against wasteful heterospecific sexual interactions, without assumptions of crossmating, gene flow, or even relatedness of interactants; the term is used in this manner for the remainder of this paper.

\section{Allochronic Isolation and Life-Cycle Evolution in Magicicada}

Because 13-year M. neotredecim and 17-year M. septendecim have parapatric distributions and are consistently distinguishable only in life cycle length, one of these two species likely originated from ancestral populations of the other (Martin and Simon 1988, 1990); the comparatively restricted range of $M$. neotredecim (Fig. 1) and the likely recent nature of its contact and reinforcement with $M$. tredecim are most consistent with recent derivation of $M$. neotredecim from $M$. septendecim (see also Simon et al. 2000). Together, these sibling species differ from 13-year M. tredecim in call pitch, abdomen coloration, and mtDNA (estimated 2.6\% divergence), suggesting separation from $M$. tredecim 1-2 million years ago (Martin and Simon 1990). If M. neotredecim is derived from $M$. septendecim, then reinforcement in $M$. neotredecim has resulted not from contact with the species' closest relative, as the process is often modeled, but from contact with a more distantly related species.

The periodical cicada complex appears to be an excellent model system for the study of speciation involving allochronic isolation (see also Alexander and Moore 1962; Simon et al. 2000): Every periodical cicada species is most closely related to a congener with the alternative life cycle, and lifecycle changes could partially or completely isolate new forms from parental populations in time (Alexander and Moore 1962). White and Lloyd (1975) found that the life-cycle difference between 13- and 17-year species can be explained by an early four-year developmental dormancy period found only in 17-year cicadas. This finding, combined with observations of apparently facultative four-year accelerations in 17-year populations (e.g., Dybas 1969; Kritsky and Simon 


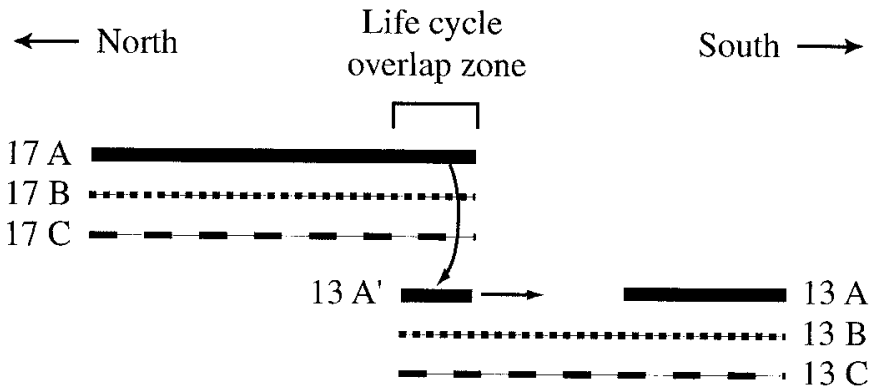

FIG. 9. Formation of an incipient Magicicada species by "nursebrood facilitation" of life-cycle mutants. Three 17-year species each have a similar 13-year counterpart, but the 13-year counterpart of species $17 \mathrm{~A}$ is not present where the life-cycle types overlap geographically. In this situation, 13-year life-cycle mutants from 17 A (curved arrow) can establish a new incipient species $\left(13 \mathrm{~A}^{\prime}\right)$ in the overlap zone if they emerge synchronously with the 13-year "nurse" brood (13 B + 13 C). Success of life- cycle mutants from $17 \mathrm{~A}$ is facilitated in the life-cycle overlap zone because $13 \mathrm{~B}$ and $13 \mathrm{C}$ provide the rare mutants with numerical protection from predators. Rare life-cycle mutants from $17 \mathrm{~B}$ and $17 \mathrm{C}$ are likely to be lost to interspecific hybridization with the similar and abundant 13 $\mathrm{B}$ and $13 \mathrm{C}$. Degree of prior divergence of $13 \mathrm{~A}$ and the parent species 17 A will influence the evolutionary outcome (mixture, hybrid zone, or reinforcement) of later contact between $13 \mathrm{~A}^{\prime}$ and $13 \mathrm{~A}$.

1996), increases the plausibility of a speciation process involving permanent four-year shifts between life-cycle types. Detailed models of such a process are difficult to construct and thus not often discussed, primarily because Magicicada populations depend on "predator satiation"' and apparently must number many thousands per hectare to avoid being destroyed by birds (Marlatt 1923; Beamer 1931; Alexander and Moore 1962; Dybas 1969; Williams et al. 1993). Two such models of Magicicada speciation by life-cycle evolution are presented below, "nurse-brood facilitation"' and "life-cycle canalization.',

Nurse-brood facilitation.-Mutations influencing life-cycle length could facilitate evolution of a new Magicicada species by allochronic isolation if a process existed by which such founders could escape predation. The observation that broods of different life cycles sometimes overlap one another in the same woods (Lloyd et al. 1983; Simon 1988) suggests such a mechanism: Life-cycle mutants from one brood could survive if their initial appearance were fortuitously timed with the emergence of a geographically overlapping brood with the same life cycle as the mutants (Fig. 9), who would then remain synchronized with the nurse brood (see also Lloyd and Dybas 1966, Simon et al. 2000). The temporal "migrants" would have to appear in numbers sufficient to permit them a chance of locating one another as conspecific mates; the need for multiple simultaneous mutants to appear at once may be mitigated by the large size of periodical cicada populations, which can reach 3.7 million per hectare (Dybas and Davis 1962) and by the possibility that a discrete developmental change underlies the life-cycle difference of 13- and 17-year species. Nurse-brood facilitation of life-cycle mutants thus suggests an explanation for the tendency of Magicicada to repeatedly evolve species-pairs with the same alternative life cycles (Alexander and Moore 1962).

Temporal migrants are most likely to successfully establish

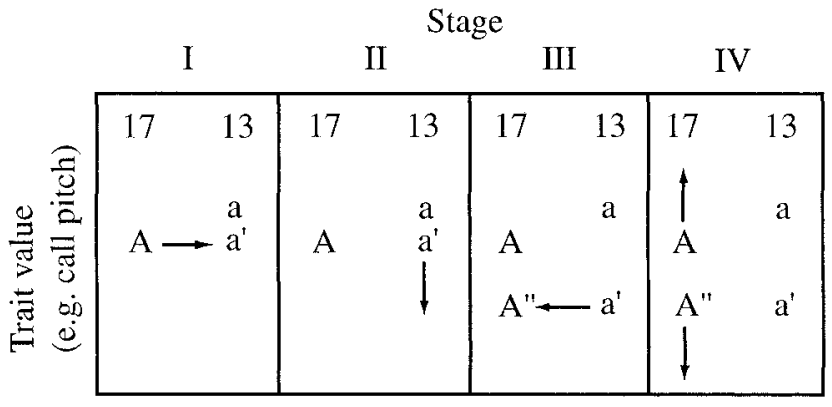

FIG. 10. A model of Magicicada speciation using nurse-brood facilitation and reinforcement to explain pairs of similar life-cycle cognates. Vertical dimension reflects degree of character divergence. Stage I: 17-year cicadas (A) mutate (to a') and join an overlapping, coemerging 13-year brood; Stage II: reinforcement occurs between $\mathrm{a}^{\prime}$ and $\mathrm{a}$ in the 13-year brood; Stage III: individuals of 13year a' mutate and join the 17-year brood, forming A" Stage IV: reinforcement occurs between A and $\mathrm{A}^{\prime \prime}$ in the 17-year brood. Our data suggest that steps I and II may have occurred. Steps III and IV are plausible by extension of the model.

themselves if the nurse brood does not already contain a confusingly similar species; the presence of such a species could result in the new mutants being lost to interspecific hybridization or failed mate location. However, prior reinforcement within a brood could alleviate this difficulty (Fig. 10) by increasing the differences between allopatric forms prior to contact. For example, reinforcement in 13-year $M$. neotredecim has incidentally caused some populations of this species to differ from nearby 17 -year M. septendecim populations in dominant chorus pitch by approximately $300 \mathrm{~Hz}$. If future 17-year life-cycle mutants from such a call-displaced $M$. neotredecim population coemerge with 17-year cicadas in the life-cycle overlap zone, the preexisting pitch differences might facilitate assortative mating of the new incipient 17year species (Fig. 10). In this model, reinforcement acts prior to speciation by causing divergence in allopatry that incidentally facilitates successful coexistence upon establishment of sympatry.

Life-cycle shifts and canalization.-Observations suggesting that Magicicada life-cycle length can be influenced by unusual climatic conditions (Alexander and Moore 1962), sometimes in four-year increments, suggest an alternative mechanism for speciation via life-cycle shift, here termed "life-cycle canalization." In this model, first presented by Lloyd and Dybas (1966), the initial isolation facilitating divergence results from the expression of latent phenotypic plasticity (e.g., West-Eberhard 1989); in contrast, under the nurse-brood model the initial isolation of the incipient species derives from intrinsic, genetic changes.

Developmental plasticity could facilitate life-cycle evolution and speciation in Magicicada if extreme climatic conditions sometimes induce periodical cicadas to switch life cycle in numbers sufficient to satiate predators and if the conditions persist for generations. Persistence of the extreme conditions would cause continued expression of the new cycle, during which time selection would favor genes that tend to canalize the new phenotype, as long as cicadas expressing the old phenotype fail to satiate predators. Furthermore, if the climate returns to the initial conditions gradually, cana- 


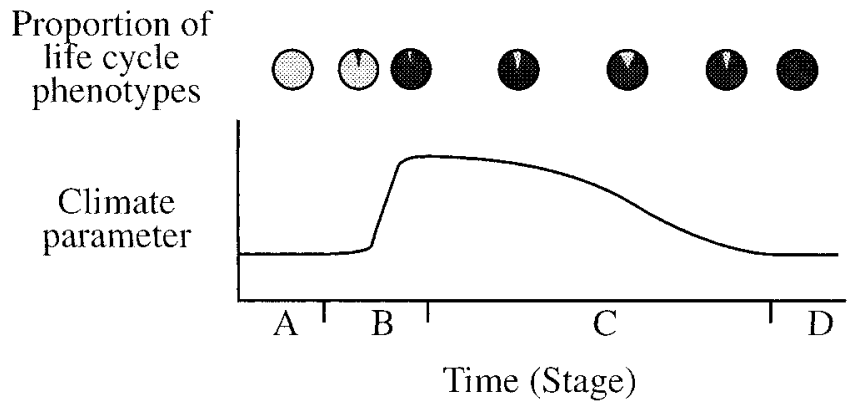

FIG. 11. A model of Magicicada life-cycle evolution via canalization of a climate-induced life-cycle shift. Graph shows temporal change in a climate parameter such as temperature. Pie charts indicate proportion of cicadas emerging in 17 years (light) and 13 years (dark). During stage A, all cicadas emerge on a 17-year cycle, but are capable of expressing life-cycle length plasticity and emerging in 13 years under unusual climatic conditions. During stage B, the climate changes suddenly and dramatically such that the majority of cicadas are induced to express the 13-year cycle. During stage $\mathrm{C}$, climatic conditions slowly ameliorate, imposing canalizing selection for the majority life-cycle phenotype of 13 years because 17-year stragglers are never abundant enough to survive predation. By stage D, the population has evolved to express the new 13-year cycle even under the original conditions.

lizing selection could lead to the evolution of cicadas that express the new life cycle even under the original conditions (Fig. 11; see Waddington 1953). In addition, if only small numbers of cicadas were triggered to switch life cycle, the mechanism of nurse brood facilitation could operate to shield them from predators, as in the mutation-based model above.

If different Magicicada species possess similar life cycle plasticity, a climate shift causing a change in the life cycle of one species could change sympatric species in a similar fashion, resulting in simultaneous, parallel speciation events. Thus, if M. neotredecim was formed from populations of $M$. septendecim by canalization of a climate-induced life cycle, we might expect to find that similar undiscovered 13-year M.-cassini and M.-decula species coexist with M. neotredecim.

\section{ACKNOWLEDGMENTS}

R. D. Alexander, D. Ciszek, L. Cooley, T. E. Moore, D. Otte, C. Simon, and two anonymous reviewers provided helpful criticism. J. Zyla of the Battle Creek Cypress Swamp Nature Center, Calvert County, Maryland, provided tape recordings and distributions of Magicicada in Maryland. We are indebted to the Harold E. Alexander Wildlife Management Area, Sharp County, Arkansas, and to M. Downs, Jr. for permission to work at the study sites. Funding was provided by the Frank W. Ammermann Endowment of the UMMZ Insect Division and by Japan Television Workshop Co., Ltd.

\section{Literature Cited}

Alexander, R. D. 1967. Acoustical communication in arthropods. Annu. Rev. Entomol. 12:495-526.

1968. Life cycle origins, speciation, and related phenomena in crickets. Q. Rev. Biol. 43:1-41.

Alexander, R. D., and R. S. Bigelow. 1960. Allochronic speciation in field crickets, and a new species, Acheta veletis. Evolution 14:334-346.

Alexander, R. D., and T. E. Moore. 1958. Studies on the acoustical behavior of seventeen-year cicadas (Homoptera: Cicadidae: Magicicada). Ohio J. Sci. 58:107-127.

- 1962. The evolutionary relationships of 17-year and 13year cicadas, and three new species. (Homoptera: Cicadidae, Magicicada). Univ. Mich. Mus. Zool. Misc. Publ. 121.

Arnold, M. 1997. Natural hybridization and evolution. Oxford Univ. Press, New York.

Beamer, R. H. 1931. Notes on the 17-year cicada in Kansas. J. Kans. Entomol. Soc. 4:53-58.

Blair, W. F. 1955. Mating call and stage of speciation in the $M i-$ crohyla olivacea-M. carolinensis complex. Evolution 9:469-480.

Brown, W. L., and E. O. Wilson. 1956. Character displacement. Syst. Zool. 5:49-64.

Butlin, R. K. 1987. Speciation by reinforcement. Trends Ecol. Evol. 2:8-13.

1989. Reinforcement of premating isolation. Pp. 158-179 in D. Otte and J. A. Endler, eds. Speciation and its consequences. Sinauer, Sunderland, MA.

. 1995. Reinforcement: an idea evolving. Trends Ecol. Evol. 10:432-434.

Cooley, J. R. 1999. Sexual behavior in North American cicadas of the genera Magicicada and Okanagana. Ph.D. diss., The University of Michigan, Ann Arbor, MI.

Coyne, J. A., and H. A. Orr. 1989. Patterns of speciation in Drosophila. Evolution 43:362-381.

. 1997. "Patterns of speciation in Drosophila" revisited. Evolution 51:295-303.

de Queiroz, K. 1998. The general lineage concept of species, species criteria, and the process of speciation. Pp. 57-78 in D. J. Howard and S. H. Berlocher, eds. Endless forms: species and speciation. Oxford Univ. Press, New York.

Dobzhansky, Th. 1940. Speciation as a stage in evolutionary divergence. Am. Nat. 74:312-321.

Doolan, J. M., and D. Young. 1989. Relative importance of song parameters during flight phonotaxis and courtship in the bladder cicada Cystosoma saundersii. J. Exp. Biol. 141:113-131.

Dybas, H. S. 1969. The 17-year cicada: a four-year mistake? Field Mus. Nat. Hist. Bull. 40:10-12.

Dybas, H. S., and D. D. Davis. 1962. A population census of seventeen-year periodical cicadas (Homoptera: Cicadidae: Magicicada). Ecology 43:432-444.

Dybas, H. S., and M. Lloyd. 1974. The habitats of 17-year periodical cicadas (Homoptera: Cicadidae: Magicicada spp.). Ecol. Monogr. 44:279-324.

Fouquette, M. J. 1975. Speciation in chorus frogs. I. Reproductive character displacement in the Pseudacris nigrita complex. Syst. Zool. 24:16-22.

Gerhardt, H. C. 1994. Reproductive character displacement of female mate choice in the grey treefrog, Hyla chrysoscelis. Anim. Behav. 47:959-969.

Grant, P. 1972. Convergent and divergent character displacement. Biol. J. Linn. Soc. 4:39-68.

Grant, P. R., and B. R. Grant. 1992. Hybridization of bird species. Science 256:193-197.

Harrison, R. G. 1979. Speciation in North American field crickets: evidence from electrophoretic comparisons. Evolution 33: 1009-1023.

Harrison, R. G., and S. M. Bogdanowicz. 1995. Mitochondrial DNA phylogeny of North American field crickets: perspectives on the evolution of life cycles, songs, and habitat associations. J. Evol. Biol. 8:209-232.

Howard, D. J. 1993. Reinforcement: origin, dynamics, and fate of an evolutionary hypothesis. Pp. 46-69 in R. G. Harrison, ed. Hybrid zones and the evolutionary process. Oxford Univ. Press, New York.

Kelly, J. K., and M. A. Noor. 1996. Speciation by reinforcement: A model derived from studies of Drosophila. Genetics 143: 1485-1497.

Kritsky, G., and S. Simon. 1996. The unexpected 1995 emergence 
of periodical cicadas (Homoptera: Cicadidae: Magicicada) in Ohio. Ohio J. Sci. 96:27-28.

Liou, L. W., and T. D. Price. 1994. Speciation by reinforcement of premating isolation. Evolution 48:1451-1459.

Littlejohn, M. J. 1965. Premating isolation in the Hyla ewingi complex (Anura: Hylidae). Evolution 19:234-243.

Littlejohn, M. J., and J. J. Loftus-Hills. 1968. An experimental evaluation of premating isolation in the Hyla ewingi complex (Anura: Hylidae). Evolution 22:659-663.

Lloyd, M., and H. S. Dybas. 1966. The periodical cicada problem. II. Evolution. Evolution 20:466-505.

Lloyd, M., and J. White. 1976. Sympatry of periodical cicada broods and the hypothetical four-year acceleration. Evolution 30: 786-801.

Lloyd, M., G. Kritsky, and C. Simon. 1983. A simple Mendelian model for the 13- and 17-year life cycle of periodical cicadas, with historical evidence for hybridization between them. Evolution 37:1162-1180.

Loftus-Hills, J. J., and M. J. Littlejohn. 1992. Reinforcement and reproductive character displacement in Gastrophryne carolinensis and G. olivacea (Anura: Microhylidae): a reexamination. Evolution 46:896-906.

Maier, C. T. 1982. Abundance and distribution of the seventeenyear periodical cicada, Magicicada septendecim (Linnaeus) (Hemiptera: Cicadidae, Brood II), in Connecticut. Proc. Entomol. Soc. Wash. 84:430-439.

Marlatt, C. L. 1923. The periodical cicada. U.S. Department of Agriculture, Bureau of Entomology Bulletin, no. 71.

Martin, A. P., and C. Simon. 1988. Anomalous distribution of nuclear and mitochondrial DNA markers in periodical cicadas. Nature 336:237-239.

1990. Differing levels of among-population divergence in the mitochondrial DNA of periodical cicadas related to historical biogeography. Evolution 44:1066-1080.

Noor, M. A. 1995. Speciation driven by sexual selection in Drosophila. Nature 375:674-675.

Otte, D. 1989. Speciation in Hawaiian crickets. Pp. 482-526 in D. Otte and J. A. Endler, eds. Speciation and its consequences. Sinauer, Sunderland, MA.

Paterson, H. E. H. 1993. Evolution and the recognition concept of species. Johns Hopkins Univ. Press, Baltimore, MD.

Rice, W. R., and E. E. Hostert. 1993. Laboratory experiments on speciation: What have we learned in 40 years? Evolution 47: 1637-1653.

Simon, C. 1988. Evolution of 13- and 17-year periodical cicadas (Homoptera: Cicadidae: Magicicada). Bull. Entomol. Soc. Am. 34:163-176.

Simon, C., J. Tang, S. Dalwadi, G. Staley, J. Deniega, and T. Unnasch. 2000. Restricted gene flow between 13-year cicadas and coexisting " 17 -year cicadas with 13-year life cycles." Evolution 54:1326-1336.

Tauber, C. A., and M. J. Tauber. 1977a. A genetic model for sympatric speciation through habitat diversification and seasonal isolation. Nature 268:702-705.

- 1977b. Sympatric speciation based on allele changes at three loci: evidence from natural populations in two habitats. Science 197:1298-1299.

Waage, J. K. 1979. Reproductive character displacement in Calopteryx (Odonata: Calopterygidae). Evolution 33:104-116.

Waddington, C. H. 1953. Genetic assimilation of an acquired character. Evolution 7:118-126.

Walker, T. J. 1974. Character displacement in acoustic insects. Am. Zool. 14:1137-1150.

Weber, T., T. E. Moore, F. Huber, and U. Klein. 1988. Sound production in periodical cicadas (Homoptera: Cicadidae: Magicicada septendecim, M. cassini). Pp. 329-336 in C. Vidano and A. Arzone, eds. Proceedings Consiglio Nazionale delle Ricerche, 6th Auchenorrhyncha meeting. Turin, Italy.

West-Eberhard, M. J. 1983. Sexual selection, social competition, and speciation. Q. Rev. Biol. 58:155-183.

. 1989. Phenotypic plasticity and the origins of diversity. Annu. Rev. Ecol. Syst. 20:249-278.

White, J., and M. Lloyd. 1975. Growth rates of 17- and 13-year periodical cicadas. Am. Midl. Nat. 94:127-143.

Williams, K. S., and C. Simon. 1995. The ecology, behavior, and evolution of periodical cicadas. Annu. Rev. Entomol. 40: 269-295.

Williams, K. S., K. G. Smith, and F. M. Stephen. 1993. Emergence of 13-yr periodical cicadas (Cicadidae: Magicicada): phenology, mortality, and predator satiation. Ecology 74:1143-1152.

Young, D., and R. K. Josephson. 1983. Pure-tone songs in cicadas with special reference to the genus Magicicada. J. Comp. Physiol. 152:197-207.

Corresponding Editor: J. Mallet

\section{APPENDIX \\ Species Description}

Magicicada neotredecim, new species.-Holotype (male): Collected by J. R. Cooley and D. C. Marshall on 18 May 1998 in Sharp County, Arkansas, in a powerline right-of-way on County Rd. 51 approximately 0.25 miles south of County Road $62\left(36^{\circ}, 15.36^{\prime} \mathrm{N}\right.$; $91^{\circ}, 27.72^{\prime} \mathrm{W}$ ), outside the Harold E. Alexander Wildlife Management Area. Dominant pitch of male call phrase $1.68 \mathrm{kHz}$. Deposited at the University of Michigan Museum of Zoology (UMMZ), Ann Arbor, Michigan, with a digital recording of the male's call. For comparative description see Table 1. Allotype: Collected by Cooley and Marshall on 18 May 1998 at the same location as holotype. Deposited at UMMZ. 